\title{
Clinical-Diagnostic Correlations in Laryngopharyngeal Reflux (LPR). The Role of Peptest ${ }^{\mathrm{TM}}$
}

\author{
Gelardi $\mathbf{M}^{{ }^{*}}$, Eplite $\mathrm{A}^{1}$, Mezzina $\mathrm{A}^{\mathbf{1}}$, Taliente $\mathrm{S}^{\mathbf{1}}$, Plantone $\mathrm{F}^{1}$, Dettmar $\mathrm{PW}^{2}$, Quaranta $\mathrm{N}^{1}$ \\ ${ }^{1}$ Department of Basic Medical Science, Neuroscience and Sensory Organs, University of Bari "Aldo Moro", Bari, Italy
}

${ }^{2}$ Managing Director, RD Biomed Ltd, Castle Hill Hospital, Cottingham Hull, East Yorkshire, HU16 5JQ, UK

Received: April 03, 2017; Accepted: May 04, 2017; Published: May 20, 2017

*Corresponding author: Gelardi M, Department of Basic Medical Science, Neuroscience and Sensory Organs, University of Bari "Aldo Moro", Bari, Italy, E-mail: gelardim@inwind.it

\begin{abstract}
LaryngoPharyngeal Reflux (LPR) is a term recently described, classified among the "extra-esophageal disorders", caused by another pathology called "Gastro-Esophageal Disease" (GED). Pepsin has been recognized as the true marker and the responsible factor of mucosal damage.
\end{abstract}

The clinical-instrumental diagnosis of LPR is mainly based upon video laryngoscopy exam, $\mathrm{pH}$-measuring, $\mathrm{pH}$-impedance measuring, using "score" questionnaires, designed to establish the presence of specific symptoms (Reflux Symptom Index - RSI) and endoscopic signs (Reflux Finding Score-RFS). The evidence of the role of pepsin associated to the LPR helped to develop new technologies, able to detect the presence of that enzyme within the saliva; this device is called Peptest ${ }^{\mathrm{TM}}$

The aim of the present study was to correlate the qualitativequantitative values of salivary pepsin (using Peptest ${ }^{\mathrm{TM}}$ ) with symptoms and signs obtained from RSI and RFS. The final goal is to validate this enzyme immunoassay method using LPR diagnostic tools.

Seventy-five patients were recruited (41 females, 34 males) aged between 12 and 71 years old, (average age 45 years). All patients performed anamnesis, including food habits analysis, RSI evaluation, rhinofibrolaryngoscopy exam with RFS calculation and Peptest $^{\mathrm{TM}}$

Highly comparable results were obtained in all of the 75 patients undergoing double detection of Peptest ${ }^{\mathrm{TM}}$, with LFD measure ( $\mathrm{T}$ band intensity) and pepsin concentration $(\mathrm{ng} / \mathrm{ml})$.

Statistically significant correlation concerning symptoms and saliva pepsin concentration was demonstrated as well as the relationship between objective signs and saliva pepsin concentration

The Peptest ${ }^{\mathrm{TM}}$ could become the "Gold standard" in all cases LPR pathology suspicion and may allow revealing the symptoms of that pathology at its early onset, avoiding dealing with more invasive methods and helping to adopt the correct therapeutic follow-up as soon as possible.

Keywords: Peptest ${ }^{\mathrm{TM}}$; Laryngopharyngeal Reflux; Gastroesophageal Reflux; Therapy.

\section{Introduction}

LaryngoPharyngeal Reflux (LPR) is a term recently described, classified among the "extra-esophageal disorders" caused by another well-known pathology called "Gastro-Esophageal Disease" (GED) [1,2]. The first insight that can be found in literature, concerning the possible involvement of ENT anatomical structures in the reflux pathology, goes back to 1903; in fact, Coffin speculated "gas reflux from the stomach" as well as the "hyper-acidity" could be considered responsible for hoarseness and back rhinorrhea [1-4]. Starting from the ' 80 s, besides the relatively "old" knowledge of GED, a new concept arose; it proposed LPR could have been caused by "acid vapors" action, coming from the stomach. Those vapors, after being in contact with the esophageal mucosa and having passed through the Upper Esophageal Sphincter (UES), reach the upper respiratory tract: larynx, laryngopharynx, and finally the nose sinus area $[3,5,18]$ and the middle ear through the auditory tubes $[1,6,7]$.

Over time, several Authors have proposed various etiopathogenetic models in order to justify the damage of upper airways and digestive tract done by LPR. Pepsin has been recognized as the true marker and the responsible factor of mucosal damage $[8-12,13]$. Pepsin is a proteolytic enzyme originated in the stomach; it is present within the acid vapors. Once in contact with the laryngopharyngeal region, it can undergo an endocytosis process thanks to a specific cellular receptor located upon the mucosal epithelial surface; subsequently, the enzyme could be activated within the Golgi apparatus, causing a sequence of biochemical reactions finally resulting in an important cell suffering $[13,16]$.

Nowadays the clinical-instrumental diagnosis of LPR is mainly based upon video laryngoscopy exam, pH measuring (esophageal, esophagopharyngeal, oropharyngeal),pHimpedance measuring, besides the use of "score" questionnaires designed to establish the presence of specific symptoms (Reflux Symptom Index - RSI) as well as endoscopic signs (Reflux Finding Score - RFS) $[14,15]$. However, the growing evidence of the role of pepsin associated to the LPR pathology has encouraged the development of new technologies, able to detect the presence 
of that enzyme within the saliva; thus leading to a device called Peptest $^{\mathrm{TM}}$ [10]. This is an innovative diagnostic device, based on immune-enzymatic test (i.e. using monoclonal antibodies) able to detect the presence of pepsin in a saliva sample with a sensitivity and specificity of, respectively, 88 and $87 \%$ [17]. It is a rapid and non-invasive test. Pepsin, thanks to this device (Peptest ${ }^{\mathrm{TM}}$ ), becomes a highly predictive marker of reflux pathology, if detected outside the gastric tract.

\section{Scope of the study}

The aim of the present study, using one of the most recent diagnostic methods known as Peptest ${ }^{\mathrm{TM}}$, was to correlate the qualitative-quantitative values of salivary pepsin with symptoms and signs obtained, respectively, from RSI and RFS. The final goal is to validate this enzyme immunoassay method using LPR diagnostic tools.

\section{Materials and methods}

Seventy-five patients were recruited (41 females, 34 males) aged between 12 and 71 years old, (average age 45 years), among those seen in the Rhino-Allergology outpatient clinic at "U.O. Otorinolaringoiatria" of Policlinico Universitario in Bari (Italy), from May 2015 to January 2016.

Out of these 75 patients, 50 (Study Group) exhibited laryngopharyngeal disorders, whereas the remaining 25 (Control Group) suffered otovestibular problems (7 dizziness, 5 tinnitus, 13 sensorineural hearing loss).

All patients performed anamnesis, including food habits analysis, RSI evaluation, rhinofibrolaryngoscopy exam with RFS calculation and Peptest ${ }^{\mathrm{TM}}$.

\section{Anamnesis}

At this stage, we consider the recent pathological anamnesis: in particular, we investigated why the patient required the physician's help. Past medical history was collected; we focused on the presence of a hypotonic LES, hiatal hernia as well as past surgeries.

Careful counseling was put in place concerning the dietary habits of each patient; it aimed to identify the "refluxinducer" food and beverages using specific charts in which the patient could select those more frequently present (at least 2 or 3 times per week) in his/her diet [29].

\section{Evaluation of Reflux Symptom Index (RSI)}

During the anamnestic evaluation, each patient had to fill "RSI" questionnaire as designed by Belafsky, in order to evaluate the possibility and/or the seriousness of LPR occurrence. The RSI questionnaire is a widely used and approved, self-administered, nine - item questionnaire for the assessment of symptoms in LPR patients. The questionnaire consists of questions regarding hoarseness, throat clearing, postnasal drip, difficulty with swallowing, coughing, breathing difficulty, troublesome cough, lump sensation, and heartburn. The patients were requested to score each symptom from 0 to 5 ( 0 meant no symptom, 5 very frequent symptoms). Although the authors considered positive for LPR a total score $\geq 13$, we thought it was more meaningful to decrease the value down to 10 (RSI cut-off), according to our previous findings (we have notice a positive Peptest ${ }^{\mathrm{TM}}$ result at this value) [14].

According to our experience, we finally included other significant symptoms for LPR diagnosis, such as: muffled ear feeling, burping; hiccup, nostril burning, conjunctiva disorders (burning and tearing).

\section{Rhinofibrolaryngoscopy exam and RFS evaluation}

The endoscopic examination of upper air and digestive ways has been carried out using a flexible rhinofibrolaryngoscope Vision Science (diameter 3.6). No patients required anaesthesiological procedures.

Important alterations of RFS calculation have been based on endoscopic evaluation of each patient. At this stage, the endoscopist assigned the score ( 0 to 4 ). An RFS value $>7$ has been assumed as pathologic.

Similarly, as far as the objective examination was concerned, we looked for the presence of further signs deemed important in view of an LPR diagnosis, e.g.: hyperemia of the nasopharynx and of the tube torus, hyperemia of the tonsil pillars and hyperemia of the uvula.

\section{Peptest $^{\mathrm{TM}}$}

All patients performed Peptest $\mathrm{T}^{\mathrm{TM}}$ using their saliva samples[ Fig $1 \mathrm{a}-\mathrm{b}$ ]

In order to guarantee the reliability of the final result, patients did not take PPI (proton pump inhibitors) or alginate based drugs, during $48 \mathrm{~h}$ before the test. Furthermore, they did not get coffee or carbonated soft drinks and did not smoke: these substances, in fact, have a reflux action. Two separate saliva samples (1 $\mathrm{ml}$ each, roughly) were collected during two successive days into graduated test tubes, within 1 hour after the main meal. Those samples not processed, were stored, refrigerated at $4^{\circ} \mathrm{C}$ with addition of $0.5 \mathrm{ml}$ of $0.01 \mathrm{M}$ citric acid, for no longer than 3 days. Each saliva sample was processed as follow: $0.5 \mathrm{ml}$ of the sample was centrifuged at $5000 \mathrm{rpm}$ for 5 minutes for obtaining supernatant; $80 \mu \mathrm{l}$ of supernatant was added to $240 \mu \mathrm{l}$ of migration buffer. After vortexing for 10 seconds, $80 \mu \mathrm{l}$ of the solution was pipetted into the well of the Peptest $^{\mathrm{TM}}$ Lateral Flow Device (LFD). The test was read after 15 minutes. The presence of a $\mathrm{C}$ band (control) indicates that the Peptest ${ }^{\mathrm{TM}}$ was correctly performed. The appearance of a second band (T) means that pepsin was present in the test sample. Since the intensity of the $\mathrm{T}$ band is directly proportional to the quantity of pepsin, the result provided by Peptest ${ }^{\mathrm{TM}}$ was both qualitative and quantitative. It is possible to get a quantitative value using the reader LFDR101®. It is an instrument, whose readout provides the pepsin concentration in $\mathrm{ng} / \mathrm{ml}$. Thanks to a special conversion table, we were able to determine the different pepsin levels originally present in the saliva samples. Finally, in order to check the reliability of the test, two readings were recorded for 


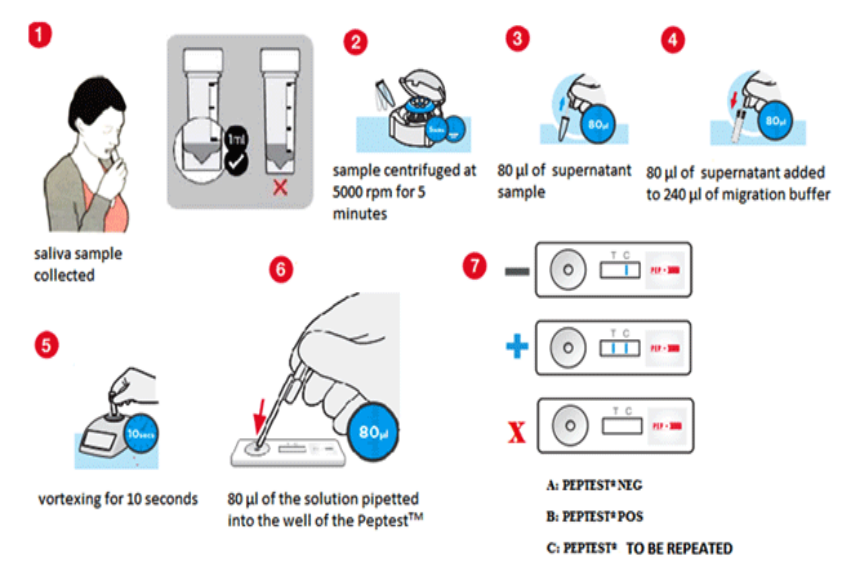

Fig 1a: Execution stages of Peptest ${ }^{\mathrm{TM}}$

Peptest $\mathrm{T}^{\mathrm{TM}}$ compared to "ELISA human pepsin detection test" is more specific for LPR. In fact, it is able to detect pepsin concentration using saliva sample, unlike ELISA rates, in blood sample, precursor protein of this enzyme: type I and II pepsinogen. Peptest ${ }^{\mathrm{TM}}$ is also considered the cheapest and the most usable test for LPR, available at the moment.

\section{Results}

Highly comparable results were obtained in all of the 75 patients undergone double detection of Peptest ${ }^{\mathrm{TM}}$, with LFD measure ( $\mathrm{T}$ band intensity) and pepsin concentration $(\mathrm{ng} / \mathrm{ml})$. The test itself can be considered reliable and reproducible [LFD $(p=0,2957)$, pepsin concentration $(p=0,2020)]$.

The sample study was divided into two groups, according to the RSI level:

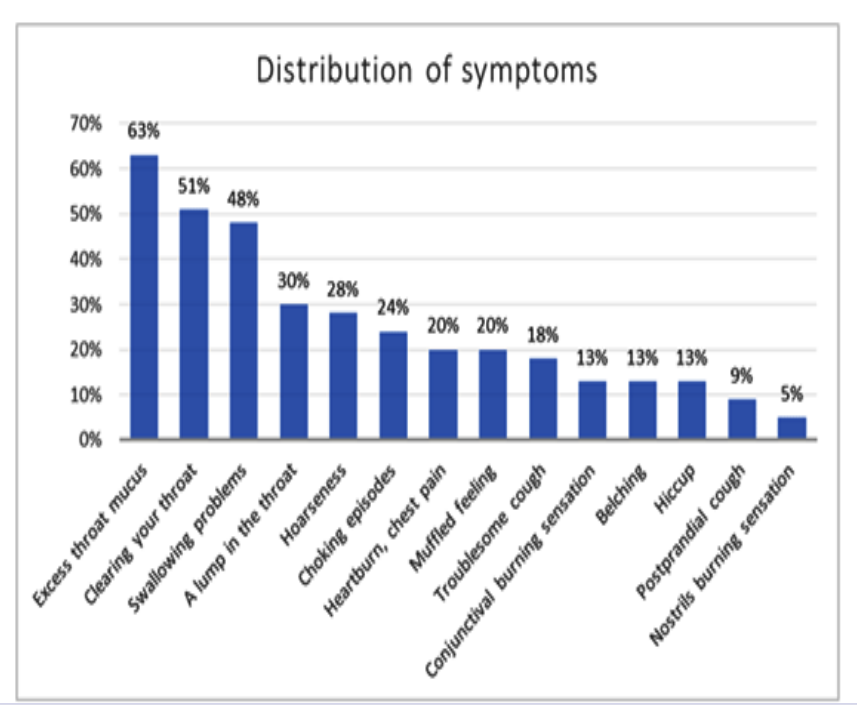

Fig 2: Remarkable symptoms reported by patients

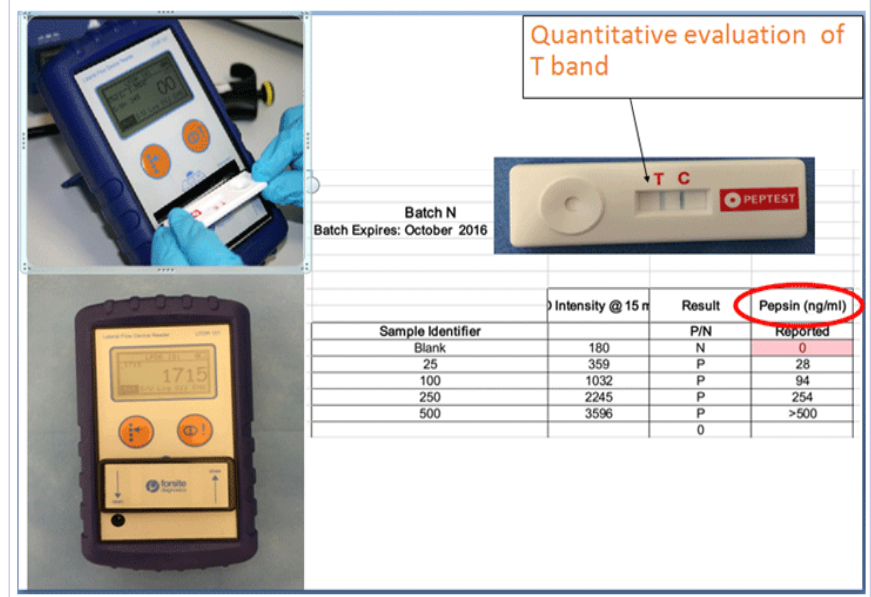

Fig 1b: Evaluation of Peptest ${ }^{\mathrm{TM}}$ results

Group 1: RSI <10;

Group 2: RSI $\geq 10$.

The two Groups were homogenous as far as the age was concerned $(p=0.1637)$ and the number of components was balanced.

As already reported, the RSI cut-off was down to 10 because of the observation that Peptest ${ }^{\mathrm{TM}}$ was positive at those levels. [Table 1,Table 2]

Fig 2 shows the most frequent symptoms described by the patients.

The correlation analysis between age, RSI value, pepsin and number of symptoms per patient, was statistically significant $(\mathrm{p}<0.005)$.

\section{Correlation between symptoms and saliva pepsin concentration}

As far as the symptoms alone were concerned, we have found a statistically significant difference between the two Groups ( $p=0.0000)$, with a higher score referred to the patients belonging to Group 2.

According to pepsin concentration, the sample was divided into 4 Groups: the first was characterized by a value of $\leq 100 \mathrm{ng} / \mathrm{ml}$ pepsin concentration; the second had values in the range $101-200 \mathrm{ng} / \mathrm{ml}$; the third $201-300 \mathrm{ng} / \mathrm{ml}$ and the last one exceeding $300 \mathrm{ng} / \mathrm{ml}$. We correlated symptom and Peptest ${ }^{\mathrm{TM}}$ value, in order to address properly the diagnosis and the therapy [Fig 3].

\section{Correlation between objective signs and saliva pepsin concentration}

As far as the correlation between the endoscopic rhinopharyngo-laryngeal signs and saliva pepsin values, we divided the study sample into three Groups: the first showed a pepsin concentration $\leq 100 \mathrm{ng} / \mathrm{ml}$, the second had values in the range $101-300 \mathrm{ng} / \mathrm{ml}$ and the third over $300 \mathrm{ng} / \mathrm{ml}$. 


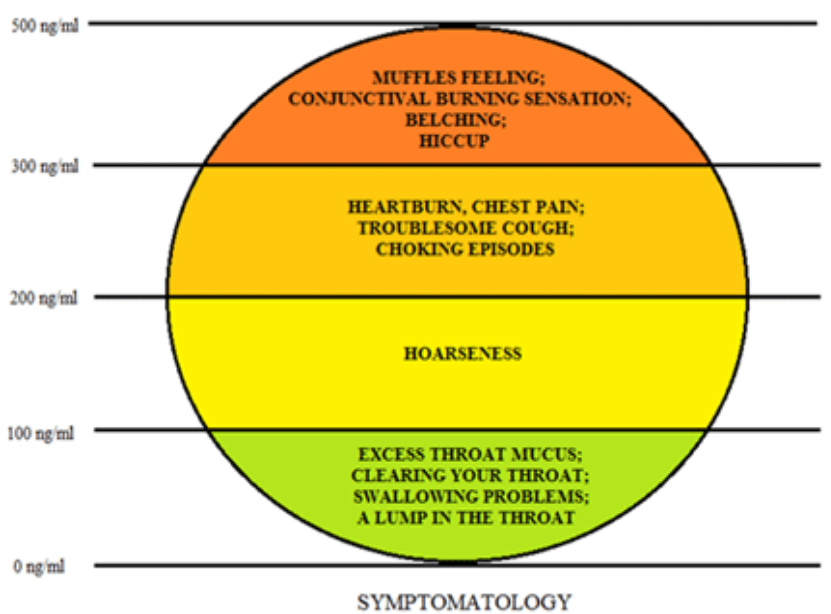

Fig 3: Correlation between symptom and Peptest $\mathrm{t}^{\mathrm{TM}}$ values
The results did demonstrate that the endoscopic signs gradually appeared along with the increase of saliva pepsin values. More specifically, nasopharynx hyperemia, sometimes related to small bruising dots together with the hyperemia of tube torus, represented the first sign associated to a low saliva pepsin concentration $(\leq 100 \mathrm{ng} / \mathrm{ml})$. When the concentration increased, (reaching values between 101 and $300 \mathrm{ng} / \mathrm{ml}$ ) we could detect the hyperemia of the palate pillars and of the uvula; the hyperemia of the arytenoids and the hypertrophy of the front commissure has been appreciated, respectively, in 50 and $40 \%$ of all cases. When the value of the saliva pepsin was above $300 \mathrm{ng} /$ $\mathrm{ml}$, hyperemia of the laryngeal face of epiglottis has been noticed in $28 \%$ of the examined patients [Table 1].

\section{Evaluation of the dietary habits}

We have considered the percentage of reflux-inducer food present in our patients' diet the diet. In 93\% of the cases we discovered the consumption of fruit (citrus fruits and citrus fruits juices),

\begin{tabular}{|c|c|c|c|c|c|c|}
\hline \multirow[b]{2}{*}{ Gender } & \multirow[b]{2}{*}{ Age } & \multirow[b]{2}{*}{ RSI } & \multicolumn{2}{|l|}{ Peptest $^{\mathrm{TM}} 1$} & \multicolumn{2}{|l|}{ Peptest $^{\mathrm{TM}} 2$} \\
\hline & & & Result P/N & Pepsin (ng/ml) & Result P/N & Pepsin (ng/ml) \\
\hline $\mathrm{F}$ & 21 & 9 & $\mathrm{P}$ & 41 & $\mathrm{P}$ & 32 \\
\hline F & 19 & 9 & $\mathrm{P}$ & 321 & $\mathrm{P}$ & 279 \\
\hline M & 57 & 8 & $P$ & 372 & $\mathrm{P}$ & 409 \\
\hline M & 55 & 8 & $\mathrm{~N}$ & 40 & $\mathrm{P}$ & 51 \\
\hline $\mathrm{F}$ & 61 & 8 & $\mathrm{P}$ & 99 & $\mathrm{P}$ & 90 \\
\hline M & 50 & 8 & $\mathrm{~N}$ & $<25$ & $\mathrm{~N}$ & $<25$ \\
\hline $\mathrm{F}$ & 21 & 8 & $\mathrm{P}$ & 175 & $\mathrm{P}$ & 144 \\
\hline M & 58 & 7 & $\mathrm{~N}$ & $<25$ & $\mathrm{~N}$ & $<25$ \\
\hline $\mathrm{F}$ & 54 & 7 & $\mathrm{P}$ & 82 & $P$ & 78 \\
\hline $\mathrm{F}$ & 31 & 7 & $\mathrm{P}$ & 100 & $\mathrm{P}$ & 85 \\
\hline M & 26 & 6 & $\mathrm{P}$ & 104 & $\mathrm{P}$ & 93 \\
\hline M & 26 & 6 & $\mathrm{~N}$ & $<25$ & $\mathrm{~N}$ & $<25$ \\
\hline $\mathrm{F}$ & 53 & 6 & $\mathrm{~N}$ & $<25$ & $\mathrm{~N}$ & $<25$ \\
\hline $\mathrm{F}$ & 42 & 6 & $\mathrm{~N}$ & $<25$ & $\mathrm{~N}$ & $<25$ \\
\hline M & 32 & 6 & $\mathrm{P}$ & 64 & $\mathrm{P}$ & 79 \\
\hline $\mathrm{F}$ & 53 & 5 & $\mathrm{~N}$ & 25 & $\mathrm{~N}$ & $<25$ \\
\hline M & 66 & 4 & $\mathrm{~N}$ & 26 & $\mathrm{~N}$ & $<25$ \\
\hline F & 12 & 4 & $\mathrm{~N}$ & $<25$ & $\mathrm{~N}$ & $<25$ \\
\hline F & 18 & 4 & $\mathrm{~N}$ & $<25$ & $\mathrm{~N}$ & $<25$ \\
\hline $\mathrm{F}$ & 28 & 3 & $\mathrm{~N}$ & $<25$ & $\mathrm{~N}$ & $<25$ \\
\hline F & 54 & 3 & $\mathrm{~N}$ & $<25$ & $\mathrm{~N}$ & $<25$ \\
\hline $\mathrm{F}$ & 65 & 3 & $\mathrm{~N}$ & $<25$ & $\mathrm{~N}$ & $<25$ \\
\hline F & 29 & 3 & $\mathrm{~N}$ & $<25$ & $\mathrm{~N}$ & $<25$ \\
\hline F & 55 & 2 & $\mathrm{~N}$ & $<25$ & $\mathrm{~N}$ & $<25$ \\
\hline M & 18 & 2 & $P$ & 57 & $P$ & 64 \\
\hline
\end{tabular}


$\mathrm{N}$ : Negative sample

Table 2: Study Group Patient

\begin{tabular}{|c|c|c|c|c|c|c|c|c|}
\hline \multirow[b]{2}{*}{ Gender } & \multirow[b]{2}{*}{ Age } & \multirow[b]{2}{*}{ RSI } & \multicolumn{3}{|c|}{ Peptest $^{\mathrm{TM}} 1$} & \multicolumn{3}{|c|}{ Peptest $^{\mathrm{TM}} 2$} \\
\hline & & & $\begin{array}{c}\text { Peptest }^{\mathrm{TM}} \\
\text { stripe intensity } \\
\text { @15 min }\end{array}$ & Result P/N & $\begin{array}{l}\text { Pepsin } \\
\text { (ng/ml) }\end{array}$ & $\begin{array}{c}\text { Peptest }^{\mathrm{TM}} \\
\text { stripe } \\
\text { intensity @15 } \\
\text { min }\end{array}$ & $\begin{array}{c}\text { Result } \\
\text { P/N }\end{array}$ & $\begin{array}{c}\text { Pepsin } \\
\text { (ng/ml) }\end{array}$ \\
\hline $\mathrm{F}$ & 52 & 39 & 6731 & $\mathrm{P}$ & $>500$ & 6124 & $\mathrm{P}$ & $>500$ \\
\hline $\mathrm{F}$ & 39 & 37 & 2150 & $\mathrm{P}$ & 240 & 2899 & $\mathrm{P}$ & 364 \\
\hline M & 25 & 35 & 1733 & $\mathrm{P}$ & 180 & 2233 & $\mathrm{P}$ & 252 \\
\hline $\mathrm{F}$ & 69 & 34 & 6357 & $\mathrm{P}$ & $>500$ & 5667 & $\mathrm{P}$ & $>500$ \\
\hline $\mathrm{F}$ & 43 & 33 & 3109 & $\mathrm{P}$ & 403 & 3481 & $\mathrm{P}$ & 475 \\
\hline $\mathrm{F}$ & 37 & 33 & 1398 & $\mathrm{P}$ & 136 & 6928 & $\mathrm{P}$ & $>500$ \\
\hline $\mathrm{F}$ & 63 & 32 & 3059 & $\mathrm{P}$ & 393 & 3499 & $\mathrm{P}$ & 479 \\
\hline $\mathrm{F}$ & 48 & 31 & 3420 & $\mathrm{P}$ & 463 & 3067 & $\mathrm{P}$ & 396 \\
\hline $\mathrm{F}$ & 18 & 31 & 1446 & $\mathrm{P}$ & 142 & 1679 & $\mathrm{P}$ & 172 \\
\hline $\mathrm{F}$ & 45 & 31 & 3043 & $\mathrm{P}$ & 390 & 4578 & $\mathrm{P}$ & $>500$ \\
\hline M & 63 & 31 & 2465 & $\mathrm{P}$ & 289 & 3008 & $\mathrm{P}$ & 384 \\
\hline M & 53 & 30 & 1850 & $\mathrm{P}$ & 196 & 5135 & $\mathrm{P}$ & $>500$ \\
\hline $\mathrm{F}$ & 43 & 30 & 3233 & $\mathrm{P}$ & 426 & 5891 & $\mathrm{P}$ & $>500$ \\
\hline $\mathrm{M}$ & 37 & 29 & 4347 & $\mathrm{P}$ & $>500$ & 4890 & $\mathrm{P}$ & $>500$ \\
\hline $\mathrm{F}$ & 39 & 27 & 4272 & $\mathrm{P}$ & $>500$ & 3978 & $\mathrm{P}$ & $>500$ \\
\hline $\mathrm{F}$ & 58 & 27 & 3008 & $\mathrm{P}$ & 384 & 2651 & $\mathrm{P}$ & 321 \\
\hline $\mathrm{F}$ & 54 & 27 & 5724 & $\mathrm{P}$ & $>500$ & 6345 & $\mathrm{P}$ & $>500$ \\
\hline $\mathrm{F}$ & 34 & 26 & 3228 & $\mathrm{P}$ & 425 & 3289 & $\mathrm{P}$ & 437 \\
\hline $\mathrm{F}$ & 50 & 26 & 3289 & $\mathrm{P}$ & 437 & 3400 & $\mathrm{P}$ & 459 \\
\hline $\mathrm{M}$ & 53 & 25 & 4040 & $\mathrm{P}$ & $>500$ & 4373 & $\mathrm{P}$ & $>500$ \\
\hline $\mathrm{M}$ & 34 & 25 & 5806 & $\mathrm{P}$ & $>500$ & 6122 & $\mathrm{P}$ & $>500$ \\
\hline M & 60 & 25 & 6316 & $\mathrm{P}$ & $>500$ & 5861 & $\mathrm{P}$ & $>500$ \\
\hline $\mathrm{F}$ & 53 & 25 & 6370 & $\mathrm{P}$ & $>500$ & 5498 & $\mathrm{P}$ & $>500$ \\
\hline $\mathrm{F}$ & 44 & 24 & 513 & $\mathrm{P}$ & 42 & 500 & $\mathrm{P}$ & 41 \\
\hline $\mathrm{F}$ & 61 & 23 & 6320 & $\mathrm{P}$ & $>500$ & 5652 & $\mathrm{P}$ & $>500$ \\
\hline $\mathrm{M}$ & 65 & 22 & 3558 & $\mathrm{P}$ & 491 & 3156 & $\mathrm{P}$ & 412 \\
\hline $\mathrm{M}$ & 71 & 21 & 3042 & $\mathrm{P}$ & 390 & 2687 & $\mathrm{P}$ & 327 \\
\hline $\mathrm{F}$ & 56 & 21 & 3457 & $\mathrm{P}$ & 470 & 3656 & $\mathrm{P}$ & $>500$ \\
\hline $\mathrm{M}$ & 42 & 20 & 1987 & $\mathrm{P}$ & 216 & 2624 & $\mathrm{P}$ & 316 \\
\hline M & 35 & 20 & 1171 & $\mathrm{P}$ & 109 & 1654 & $\mathrm{P}$ & 169 \\
\hline M & 30 & 20 & 2622 & $\mathrm{P}$ & 316 & 2189 & $\mathrm{P}$ & 246 \\
\hline $\mathrm{M}$ & 52 & 19 & 2388 & $\mathrm{P}$ & 277 & 2011 & $\mathrm{P}$ & 219 \\
\hline M & 24 & 19 & 2639 & $\mathrm{P}$ & 319 & 2789 & $\mathrm{P}$ & 345 \\
\hline $\mathrm{M}$ & 29 & 18 & 6123 & $\mathrm{P}$ & $>500$ & 6548 & $\mathrm{P}$ & $>500$ \\
\hline $\mathrm{F}$ & 37 & 18 & 6008 & $\mathrm{P}$ & $>500$ & 5678 & $\mathrm{P}$ & $>500$ \\
\hline $\mathrm{M}$ & 61 & 17 & 3820 & $\mathrm{P}$ & $>500$ & 3256 & $\mathrm{P}$ & 431 \\
\hline
\end{tabular}




\begin{tabular}{|c|c|c|c|c|c|c|c|c|}
\hline M & 45 & 16 & 839 & $\mathrm{P}$ & 72 & 1120 & $\mathrm{P}$ & 103 \\
\hline $\mathrm{F}$ & 30 & 16 & 1868 & $\mathrm{P}$ & 198 & 1145 & $\mathrm{P}$ & 106 \\
\hline M & 56 & 15 & 3989 & $\mathrm{P}$ & $>500$ & 4890 & $\mathrm{P}$ & \\
\hline $\mathrm{M}$ & 66 & 15 & 5032 & $\mathrm{P}$ & $>500$ & 4233 & $\mathrm{P}$ & \\
\hline $\mathrm{F}$ & 56 & 14 & 542 & $\mathrm{P}$ & 44 & 845 & $\mathrm{P}$ & \\
\hline $\mathrm{F}$ & 48 & 14 & 520 & $\mathrm{P}$ & 42 & 389 & $\mathrm{P}$ & \\
\hline $\mathrm{M}$ & 68 & 14 & 6611 & $\mathrm{P}$ & $>500$ & 5200 & $\mathrm{P}$ & \\
\hline $\mathrm{M}$ & 35 & 13 & 3015 & $\mathrm{P}$ & 385 & 2133 & $\mathrm{P}$ & \\
\hline $\mathrm{M}$ & 65 & 12 & 1238 & $\mathrm{P}$ & 117 & 1109 & $\mathrm{P}$ & \\
\hline $\mathrm{F}$ & 26 & 11 & 611 & $\mathrm{P}$ & 51 & 988 & $\mathrm{P}$ & \\
\hline $\mathrm{M}$ & 32 & 11 & 2216 & $\mathrm{P}$ & 250 & 1499 & $\mathrm{P}$ & \\
\hline $\mathrm{F}$ & 66 & 11 & 2600 & $\mathrm{P}$ & 312 & 2454 & $\mathrm{P}$ & \\
\hline $\mathrm{M}$ & 40 & 11 & 1539 & $\mathrm{P}$ & 154 & 1261 & $\mathrm{P}$ & \\
\hline $\mathrm{M}$ & 62 & 11 & 3005 & $P$ & 383 & 2458 & $P$ & \\
\hline
\end{tabular}

RSI: Reflux Symptoms Index

P: Positive sample

$\mathrm{N}$ : Negative sample

as well as vegetables (particularly tomato and tomato sauce). $79 \%$ of patients used to eat sweet and fat food (brioches, chocolate, cookies, etc...), 68\% meat fried food (hamburgers, chips, etc...), 64\% milk and milk derivatives, 57\% drinks (sparkling water, carbonated drinks, spirits, beer and sparkling wines), 50\% cereals and cereals derivatives and finally $37 \%$ specific refluxinducer food (spices, chewing-gum, etc) [Fig 4].

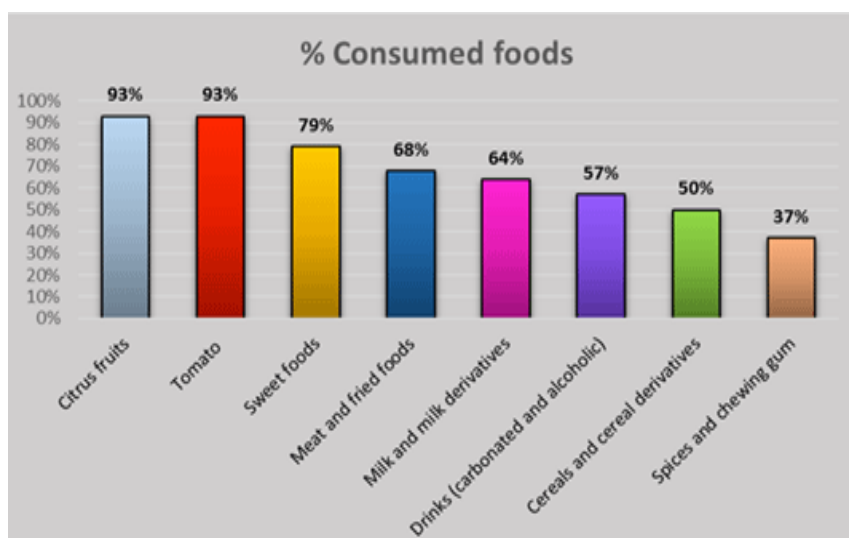

Fig 4: Percentage of reflux - inducer food in our patient's diet

\section{Control Group}

None of the 25 examined individuals showed inflammatory disorders affecting airways and digestive tract; they did not were not affected by any reliable disease; this finding was confirmed by both RSI and RFS scores, which were lower than, respectively, 10 and 7 . The same patients were negative for the Peptest ${ }^{\mathrm{TM}}$, too.

\section{Discussion}

The scientific bibliography tends to highlight the detrimental mechanism of the pepsin's action towards the mucosa of the upper airways and digestive tract, as an expression of the well-known extra-esophageal phenomena of Gastro - Esophageal Reflux Disease (GERD). Consequently, the new technologies able to detect the reflux in the extra-esophageal regions have been strongly enhanced, and, at the same time, new therapeutic strategies have been developed [12].

The present study allowed us to pick out some interesting aspects, not properly reported in literature, very useful in view of a better understanding of mechanisms of LPR pathology.

The first topic concerns the age, which represents an important element to consider in LPR pathology. Our findings seem to confirm some previous studies $[13,14]$ that emphasized a significant correlation between the increase of the age and the pepsin's increase within the esophagus. Therefore, as the age increases, we should expect an increased predisposition to LPR.

Another important aspect, not reported in literature, states that each range of pepsin concentration in saliva meets specific symptoms more and more crippling.

Starting from pepsin's level $\leq 100 \mathrm{ng} / \mathrm{ml}$, the most frequently found symptoms are: 1 -excess of pharyngeal mucus (36\%) 2-throat "raclage" (20\%); 3- throat foreign body sensation and/or swallowing problems (16\%). The above mentioned symptoms represent the LPR's onset symptoms. Despite these are "non specific" symptoms because common in several ENT pathologies, they are hardly ascribed, at a first glance, to an etiopathogenic mechanism originated in the gastric area. The same consideration can be made for those patients showing a pepsin level in the range $101-200 \mathrm{ng} / \mathrm{ml}$, where it is possible (14\%) to appreciate voice trouble (hoarse, dysphonia). The symptoms described above are just the inflammatory expression of the laryngopha- 
ryngeal mucosa, whose etiopathogenic mechanisms have been deepen just in the last few years. However, to see the symptoms related to the digestive tract, it is necessary to get higher pepsin value, between 201 and $300 \mathrm{ng} / \mathrm{ml}$ : at that level, a burning sensation behind the breastbone appeared in $17 \%$ of the patients. The low percentage of this disorder represents an additional confirmation that gastro-esophageal and laryngopharyngeal reflux are two different pathological situations. According to our clinical experience, the majority of patients suffering from LPR are unlikely to complain of gastric disorders, such as heartburn or acidity. Similarly, they are unlikely to report acid regurgitations events or digestion problems. Consequently, the existence itself of a laryngopharyngeal pathology is "de-legitimized". Actually, within the same range of saliva pepsin's values (e.g. 201-300 ng/ml), two important symptoms are frequently appreciated: the peevish cough and the laryngeal jerks (15\%) [Figure 2,3]. They impair the patient's quality of life during the daytime and even more during the sleeping hours. The diagnosis always helps the therapy! Those symptoms need to be related to LPR; otherwise, there will be a condition in which the patient keeps on consulting for many months several specialists (ENT, Respiratory Physician, Pediatrician, Gastroenterologist, Internist, Allergologist etc). That patient will undergo a number of useless and sometimes harmful examinations (chest examination, lungs CT scan, allergy and infectious diseases tests, endoscopies of the airways, etc.) usually followed by improper therapies (antibiotics, mucolytic, cough sedatives as well as anti-histamine, cortisone based drugs and bronchodilators). Whenever a peevish cough has appreciated (no fever-associated, long time lasting) in a patient who has not allergic disorders (or outside the pollen period), not using cough stimulating drugs (e.g. ACE inhibitors), then LPR must always be suspected by the physician. The laryngeal jerk often occurs during the sleeping hours; it is the expression of a defensive mechanism of the respiratory tract against the inhalation of acid vapors or juices coming from the stomach. Frequently, laryngeal jerk is misdiagnosed as an event caused by either an allergic crisis or croup. Therefore, it is recommended to carry out a careful anamnesis including the onset mode and the duration of the symptom.

Furthermore, there are some disorders rarely taken into consideration and potentially connected to LPR pathology, detected in patients with pepsin's levels exceeding $300 \mathrm{ng} / \mathrm{ml}$ : fullness i.e. the muffled ear feeling (20\%), hiccup, burping and conjunctiva disorders (13\%).

The fullness, already described as a phenomenon deriving from an LPR pathology $[19,23]$, is the expression of the congestion of the Eustachian tube mucosa, followed by the wrong ventilation of the middle ear. The correlation between LPR and auricular disorders has been reported by previous studies, even highlighting the presence of pepsin in the middle ear [19-28]. We are absolutely convinced that this mechanism does exist, to the extent of validating an endoscopic observation characterized by hyperemia of nasopharynx and of tube torus, we have included among the endoscopic signs of LPR's suspicion. The rhino-pharyngeal region, including the middle ear, the sinus cavities and even the tear ducts and the conjunctiva, represent the anatomic "terminal" stations of a long "upwards" trip done by the gastric secretions both in liquid form and (even more) as an "aerosol". This trip is enhanced by multiple factors, depending on anatomic condition (dilated cardia, hiatal hernia), dietary habits (refluxinducer food, carbonated drinks, etc.) and functional reasons (stress, sport activities etc.). Hiccup and burping, found in 13\% of patients showing a pepsin's value $>300 \mathrm{ng} / \mathrm{ml}$, can definitely enhance the above-mentioned upward trip mechanism. The same consideration can be reported for the hyperemia of arytenoids, laryngeal part of epiglottis, palate and uvula pillars (intermediate stations). Another clinically important sign of LPR suspicion is the uvula edema. It usually occurs at the waking up time in the morning: it is responsible for emergency ward consultancies more often than other disease as allergic disorders.

In terms of correlation between RSI and pepsin concentration, we noticed that for the same scoring result, a high value of the single symptom is more predictive than the sum of many symptoms. Therefore, when a patient reports a high value of a particular symptom, he will have a high value of salivary pepsin.

Finally, as far as the hygienic-dietary rules are concerned, it is necessary to underline the importance of the diet [29]. Whichever drug treatment will be prescribed to the patient, no success can be achieved in terms of LPR therapy unless not supported by a convenient counseling aimed to detect and correct the bad dietary habits [Figure 4].

Therefore, it seems necessary to reconfirm the diagnostic efficacy of the Peptest ${ }^{\mathrm{TM}}$, a test that could become the "Gold standard" in all cases of LPR pathology suspicion. It may allow revealing the symptoms of that pathology at its early onset, avoiding dealing with more invasive methods and helping to adopt the correct therapeutic follow-up as soon as possible.

\section{References}

1. Koufman JA. The otolaryngologic manifestations of gastroesophageal reflux disease (GERD): a clinical investigation of 225 patients using ambulatory 24-hour pH monitoring and an experimental investigation of the role of acid and pepsin in the development of laryngeal injury. Laryngoscope 1991;101:1-78.

2. Maldhure S, Chandrasekharan R, Dutta AK, Chacko A, Kurien M. Role of PH Monitoring in Laryngopharyngeal Reflux Patients with Voice Disorders. Iran J Otorhinolaryngol. 2016;28(89):377-383.

3. Schneider GT, Vaezi MF, Francis DO. Reflux and Voice Disorders: Have We Established Causality? Curr Otorhinolaryngol Rep. 2016;4(3):157167. doi:10.1007/s40136-016-0121-5

4. Fortunato JE, D’Agostino RB Jr, Lively MO. Pepsin in saliva as a biomarker for oropharyngeal reflux compared with 24-hour esophageal impedance/pH monitoring in pediatric patients. Neurogastroenterol Motil. 2017;29(2). doi:10.1111/nmo.12936

5. Weaver EM. Association between gastroesophageal reflux and sinusitis, otitis media, and laryngeal malignancy: a systemic review of the evidence. Am J Med. 2003;115:81S-89S.

6. Kim SI, Kwon OE, Na SY, Lee YC, Park JM, Eun YG. Association between 24-hour combined multichannel intraluminal impedance-pH monitor- 
ing and symptoms or quality of life in patients with laryngopharyngeal reflux. Clin Otolaryngol. 2017;42(3):584-591. doi:10.1111/coa.12817

7. Taubers S, Gross M, Issing WJ. Association of laryngopharyngeal symptoms with gastroesophageal reflux disease. Laryngoscope. 2002;112(5):879-886.

8. Postma GN, Tomek MS, Belafsky PC, Koufman JA. Esophageal motor function in laryngopharyngeal reflux is superior to that of classic gastroesophageal reflux disease. Ann Otol Rhinol Laryngol. 2001;110(12):1114-1116.

9. Koufman JA, Belafsky PC, Bach KK, Daniel E, Postma GN. Prevalence of esophagitis in patients with $\mathrm{pH}$-documented laryngopharyngeal reflux. Laryngoscope 2002:112:1606-1609.

10. Halum SL, Postma GN, Johnston C, Belafsky PC, Koufman JA. Patients with isolated laryngopharyngeal reflux are not obese. Laryngoscope. 2005;115(6):1042-1045.

11. Birchall MA, Bailey M, Gutowska-Owsiak D, Johnston N, Inman CF, Stokes $\mathrm{CR}$, et al. Immunologic response of the laryngeal mucosa to extraesophageal reflux. Ann Otol Rhinol Laryngol. 2008;117(12):891895.

12. Francis DO, Patel DA, Sharda R, Hovis K, Sathe N, Penson DF, et al. Patient-Reported Outcome Measures Related to Laryngopharyngeal Reflux: A Systematic Review of Instrument Development and Validation. Otolaryngol Head Neck Surg. 2016;155(6):923-935.

13. Karna Dev Bardhan, Vicki Strugala, PeterW. Dettmar. Reflux Revisited: "Advancing the Role of Pepsin". Hindawi Publishing Corporation. International Journal of Otolaryngology. 2012(2012).

14. Belafsky PC, Koufman JA, Postma GN. Validity and reliability of the reflux symptom index (RSI). J Voice. 2002;16(2):274-277.

15. Belafsky PC, Postma G N, Koufman J A. The validity and reliability of the reflux finding score (RFS). Laryngoscope. 2001;111(8):1313-1317.

16. Piper DW, Fenton BH. pH stability and activity curves of pepsin with special reference to their clinical importance. Gut 1965;6(5):506-508

17. Elif Saritas Yuksel, Shih-Kuang S. Hong, Vicki Strugala, James C. Slaughter, Marion Goutte, C. Gaelyn Garrett, et al. Rapid Salivary Pepsin Test: Blinded Assessment of Test Performance in Gastroesophageal Reflux Disease. The Laryngoscope. 2012;122(6):1312-1316•

18. Loehrl TA, et al. The role of extraesophageal reflux in medically and surgically refractory rhinosinusitis. Laryngoscope. 2012;122 (7):14251430.
19. Megale SR, Scanavini AB, Andrade EC, Fernandes MI, Anselmo-Lima WT. Gastroesophageal reflux disease: its importance in ear, nose, and throat practice. Int J Pediatr Otorhinolaryngol 2006;70(1):81-88.

20. Pawar S, Lim HJ, Gill M, Smith TL, Merati A, Toohill RJ, et al. Treatment of postnasal drip with proton pump inhibitors: a prospective randomized, placebo-controlled study. Am J Rhinol Allergy 2007;21:695-701. doi:10.2500/ajr.2007.21.3098

21. Bluestone CD. Studies in otitis media: Children's Hospital of Pittsburgh-University of Pittsburgh progress report. Laryngoscope. 2004;114(suppl 105):1-26.

22. Gilger MA. Pediatric otolaryngologic manifestations of gastroesophageal reflux disease. Curr Gastroenterol Rep. 2003;5(3):247-252.

23. Heavner SB, Hardy SM, White DR, Prazma J, Pillsbury HC 3rd. Transient inflammation and dysfunction of the eustachian tube secondary to multiple exposures of simulated gastroesophageal refluxant. Ann Otol Rhinol Laryngol. 2001;110(10):928-934.

24. Sudhoff H, Bücker R, Groll C, Shagdarsuren S, Dazert S, Schreiber S. Tracing of gastric reflux into the middle ear in a mongolian gerbil model. Otol Neurotol. 2007;28(1):124-128.

25. Tasker A, Dettmar PW, Panetti M, Koufman JA, P Birchall J, Pearson JP. Is gastric reflux a cause of otitis media with effusion in children? Laryngoscope. 2002;112:1930-1934.

26. O'Reilly RC, He Z, Bloedon E, Papsin B, Lundy L, Bolling L, et al. The role of extraesophageal reflux in otitis media in infants and children. Laryngoscope. 2008;118(7 Part 2 Suppl 116):1-9.

27. Mahdavinia M, Bishehsari F, Hayat W, Codispoti CD, Sarrafi S, Husain I, et al. Prevalence of allergic rhinitis and asthma in patients with chronic rhinosinusitis and gastroesophageal reflux disease. Ann Allergy Asthma Immunol. 2016;117(2):158-162e1. doi:10.1016/j. anai.2016.05.018

28. Buyruk A, Osma Ü, Yılmaz MD, Eyigör H. Pepsinogen identification in the middle ear fluid of children with otitis media with effusion. 2016;26(2):73-78. doi:10.5606/kbbihtisas.2016.83669

29. Caselli M, Zuliani G, Cassol F, Fusetti N, Zeni E, Lo Cascio N, et al. Test-based exclusion diets in gastro-esophageal reflux disease patients: a randomized controlled pilot trial. World J Gastroenterol. 2014;20(45):17190-17195. doi:10.3748/wjg.v20.i45.17190 